\title{
Pembinaan Akhlak Siswa Oleh Guru Pendidikan Agama Islam Di SMP Negeri 10 Lebong
}

\author{
Suryono $^{1 *}$, Ahmad Dibul Amda ${ }^{2}$, Sutarto $^{3}$ \\ ${ }^{123}$ Prodi Pendidikan Agama Islam, Pascasarjana, IAIN Curup \\ Email : suryonoyono16433@ gmail.com ${ }^{1 *}$
}

\begin{abstract}
This study aims to describe the efforts to develop students' morals by PAI teachers at SMP Negeri 10 Lebong in addition to knowing what obstacles were found in efforts to foster students' morals by PAI teachers at SMP Negeri 10 Lebong. This research is expected to make a scientific contribution to the development of science, especially PAI and Student Moral Development in schools. This research is a research (field research) and the use of a qualitative descriptive approach. The data and sources of data in this study are Islamic religious education teachers and school principals. Data collection techniques using observation, interviews and documentation. The data analysis technique has 3 stages, namely data reduction, data presentation and conclusion drawing. In research the data must be acceptable to support the conclusions of the study. Therefore, it is necessary to use data validity standards consisting of: 1. credibility, 2. transferability, 3. dependability, 4. comfirmability. From the results of the research carried out in this study, it is the moral development of students by PAI teachers through PAI learning at SMP Negeri 10 Lebong, including the habituation method, the exemplary method, the storytelling method and the historical method. In addition, the moral development of students by PAI teachers is also carried out through religious extracurricular activities at SMP Negeri 10 Lebong such as the implementation of congregational and timely prayers, BTQ activities (Read, then through Lectures, Advice and Stories or History stories, as well as monitoring with parents/guardians of students In the implementation of moral development, of course, there are several obstacles including First, the lack of means of communication, the second factor is the lack of good transportation facilities, the third factor is the current Covid-19 pandemic which requires learning processes and extracurricular activities in fostering students' morals carried out by BDR (Learning From Home).
\end{abstract}

Keywords: Moral, PAI, SMP Negeri 10 Lebong.

\begin{abstract}
Abstrak
Penelitian ini bertujuan untuk mendeskripsikan upaya pembinaan akhlak siswa Oleh Guru PAI di SMP Negeri 10 Lebong selain itu untuk mengetahui apa kendala yang ditemukan dalam upaya pembinaan akhlak siswa Oleh Guru PAI di SMP Negeri 10 Lebong. Penelitian ini diharapkan dapat diharapkan dapat memberikan kontribusi ilmiah bagi pengembangan ilmu pengetahuan, khususnya mengenai PAI dan Pembinaan Akhlak Siswa disekolah. Penelitian ini ialah penelitian lapangan ( field research ) dan menggunakan pendekatan deskriptif kualitatif. Data dan sumber data dalam penelitian adalah guru pendidikan agama Islam dan kepala sekolah. Teknik pengumpulan data menggunakan observasi, wawancara dan dokumentasi. Adapun teknik analisis data terdapat 3 tahapan yakni reduksi data, menyajikan data dan penarikan kesimpulan. Dalam penelitian data harus dapat diterima untuk mendukung kesimpulan penelitian. Oleh karena itu perlu dipakai standar keshahihan data yang terdiri dari: 1. keterpercayaan (credibility), 2. dapat keteralihan (transferabilty), 3. keterandalan (dependability), 4. komfirmabilitas (comfirmability). Dari hasil penelitian yang dilakukan pada penelitian ini adalah Pembinaan Akhlak siswa oleh Guru PAI melalui pembelajaran PAI di SMP Negeri 10 Lebong, antara lain dengan metode pembiasaan, metode teladan, metode bercerita dan metode sejarah. Selain itu pembinaan akhlak siswa oleh Guru PAI juga dilaksanakan melalui kegiatan ekstrakurikuler keagamaan di SMP Negeri 10 Lebong seperti pelaksanaan solat berjamaah dan tepat waktu, kegiatan BTQ (Baca, kemudian melalui Ceramah, Nasehat dan Cerita Kisah atau sejarah, serta monitoring dengan orangtua/wali siswa. Dalam pelaksanaan pembinaan akhlak tentunya menemui beberapa kendala diantaranya ialah Pertama, Faktor kurangnya sarana komunikasi, Kedua faktor sarana transfortasi yang kurang baik, Ketiga Faktor keadaan Pandemi Covid-19 saat ini yang mengharuskan proses pembelajaran dan kegiatan ekstrakurikuler dalam pembinaan akhlak siswa dilaksanakan BDR (Belajar Dari Rumah).
\end{abstract}

Kata Kunci: Akhlak, PAI, SMP Negeri 10 Lebong.

\section{PENDAHULUAN}

Ketaqwaan serta keimanan dapat mengalami peningkatan setelah peserta didik menempuh pendidikan. Setelah menempuh pendidikan harapan nya peserta didik memiliki akhlak mulia. Selain itu untuk menciptakan seseorang yang religius juga bisa melalaui pendidikan khususnya pendidikan agama islam. Kehidupan manusia dapat berkembang sebagai hasil dari pendidikan. Setelah nilai pendidikan telah terbentuk, upaya peningkatan kualitas proses pembelajaran harus terus dilaksanakan 
untuk mendapatkan hasil yang sebaik-baiknya (Sulistyorini, 2009).

Pada sisi lain sekolah memainkan peran penting dalam membantu orang tua dalam menanamkan kebiasaan yang baik dan menumbuhkan karakter yang terpuji pada anakanak mereka. Selain itu, pendidikan di dalam keluarga bisa dilanjutkan di sekolah untuk hasil yang lebih optimal (Daulay, 2014).

Pada hakikatnya setiap anak yang dilahirkan sudah memiliki kecintaan terhadap agama. Rasa cinta itu akan terus tumbuh apabila ia telah memahami dan menerima pendidikan. Mendidik anak untuk faham agama penting sekali dilaksanakan sejak masa kecil sebab seseorang yang sudah dewasa namun ketika kecil sama sekali tidak memiliki pengetahuan agama, maka kelak dia bisa mengabaikan kehadiran agama dalam kehidupan nya.

Pengajaran agama untuk anak- anak bisa dimulai dari pengalaman dalam keluarga, di sekolah dan dalam masyarakat. Anak yang ketika kecil diajarkan agama ketika kelak dewasa akan merasakan bahwa agama itu begitu penting dalam hidup mereka, selain itu semakin besar pemahaman agama yang diketahui anak maka akan semakin sedikit kemungkinan mereka akan melakukan kejahatan, perilaku tercela, kebohongan ketika dewasa. Seorang anak yang terlahir di dunia keadaan jiwa nya akan sangat terpengaruh oleh bagaimana kondisi orang tua sebelum diri nya dilahirkan (Daraat, 2009)

Dari apa yang telah dipaparkan diatas sudah bisa disimpulkan bahwa sudah sepatutnya sejak kecil anak diberikan dasar pendidikan agama itu, sebab bagaimana sikap dan perilaku anak ketika dewasa itu merupakan gambaran apa yang mereka dapatkan semasa kecil. Apabila seseorang ketika masa anak- anak dikenalkan siapa pencipta nya, diajarkan ilmu agama, belajar mengaji, juga mengenyam pendidikan sejak sekolah dasar hingga perguruan tinggi maka ketika dewasa orang tersebut dapat bermanfaat bagi orang dan menjauhi perilaku tidak terpuji serta merasakan betapa penting nya agama bagi hidup nya.

Kajian tentang pembinaan akhlak sudah sering ditemukan seperti penelitian yang dilakukan oleh Sri Sapitri Aryanti yang berjudul "Pengaruh Aktivitas Pembelajaran PAI Terhadap
Akhlak Siswa" penelitian ini membahas tentang pola fikir bahwa untuk membentuk akhlak siswa di sekolah salah satunya dengan mengajarkan mata pelajaran PAI, namun sepanjang yang peneliti ketahui belum ada yang membahas mengenai pembinaan akhlak yang dilaksanakan oleh guru PAI.

Kajian tentang pembinaan akhlak memang perlu dilaksanakan sebab berdasarkan observasi pra-penelitian, di dapat informasi bahwa di SMP Negeri 10 Lebong, Pembinaan akhlak siswa diembankan atau dititik beratkan pada pelajaran PAI dan kegiatan ekstrakurikuler keagamaan. Pelajaran PAI merupakan mata pelajaran yang begitu diharapkan dapat membina akhlak siswa. Yang bertujuan untuk menciptakan generasi yang memiliki kompetensi dan mampu berkompetisi, beriman dan bertakwa kepada Tuhan Yang Maha Esa serta berakhlakul karimah. Selain itu peneliti menmperoleh informasi bahwa di sekolah tersebut selalu mengadakan acara Peringatan Maulid dan Isra Mikraj Nabi Muhammad Saw sebagai upaya memperingati serta menghargai hari-hari besar islam, selain itu kerapkali mengadakan lomba dengan nuansa islami . Dalam membina akhlak siswa di SMP Negeri 10 Lebong pihak sekolah menekankan pada aspek kegiatan ekstrakurikuler keagamaan juga mata pelajaran PAI.

Ada beberapa tujuan yang ingin dicapai peneliti pada penelitian ini antara lain: (1) Mendeskripsikan Pembinaan Akhlak siswa Oleh Guru PAI di SMP Negeri 10 Lebong (2) Mengungkap Kendala yang dihadapi dalam pembinaan akhlak siswa di SMP Negeri 10 Lebong .

\section{METODE}

Penelitian ini ialah penelitian lapangan (field research), maknanya ialah sumber data didapatkan di lapangan, seperti di masyarakat, lembaga dan kelompok masyarakat, serta lembaga pendidikan formal ataupun nonformal (Moleong, 2011). Sementara pendekatan yang dipakai ialah pendekatan deskriptif kualitatif. Pada penelitian ini dilaksanakan di SMP Negeri 10 Lebong Kecamatan Lebong Utara Kabupaten Lebong.

Data yang dikumpulkan pada penelitian ini ialah data kualitatif yang dikumpulkan 
melalui dua cara yakni data primer yakni data yang didapat secara langsung dari subyek terteliti pada saat penelitian dilaksanakan berupa data guru di SMP Negeri 10 Lebong, dan data sekunder yakni data yang dimaksudkan untuk melengkapi data primer dari kegiatan penelitian bersumber dari data lisan, dokumentasi dan sumber-sumber kepustakaan.

Dalam penelitian ini teknik pengumpulan yang penulis gunakan berupa observasi, wawancara, angket (questionnaires), dokumentasi, atau kombinasi keempatnya. Observasi yang dilaksanakan ialah Observasi partisipasi pasif (passive participation) Yakni dalam hal ini peneliti hadir ditengah masyarakat yang melaksanakan kegiatan yang diteliti, tetapi tidak ikut terlibat dalam kegiatan tersebut. Adapun peneliti akan melakukan observasi dengan mendatangi SMP Negeri 10 Lebong untuk melihat proses Pembelajaran PAI dan kegiatan Pembinaan Akhlak. Wawancara ialah proses tanya jawab lisan, dalam mana dua orang atau lebih berhadapan secara fisik, yang satu dapat melihat muka yang lain dan mendengar dengan telinga sendiri dari suaranya (Sukandarrumi, 2014). Teknik wawancara bebas terpimpin digunakan dalam penelitian ini, , dimana peneliti sudah membawa daftar pertanyaan namun juga menanyakan hal-hal lain yang terkait dengan penjelasan yang telah dipaparkan oleh subyek penelitian. Setelah itu, peneliti akan mendokumentasikan data yang sudah terkumpul berupa analisis arsip tertulis dari kepala sekolah dan dokumen dari Guru PAI SMP Negeri 10 Lebong.

Menurut Moeleong (2011), data hasil wawancara dan observasi dianalisis dalam tiga tahapan berikut ini adalah tahapan analisis data.

1. Reduksi data

Manfaat reduksi data ini ialah untuk menggambarkan dengan jelas data yang sedang diteliti. Apabila peneliti membutuhkan informasi tambahan, peneliti dapat segera mencari informasi itu di lokasi penelitian.

2. Penyajian data

Melalui tahap ini, peneliti dapat menyajikan data dalam bentuk deskripsi singkat, hubungan antarunsur, kategori, gambar, dan bagan.

\section{Verifikasi data}

Pada proses ini, peneliti melaksanakan pengambilan kesimpulan atas data-data yang sudah terkumpul (Arikunto, 2002).

Dalam penelitian data harus dapat diterima untuk mendukung kesimpulan penelitian. Oleh karena itu perlu dipakai standar keshahihan data yang terdiri dari: 1 . keterpercayaan (credibility), 2. dapat keteralihan (transferabilty), 3. keterandalan (dependability), 4. komfirmabilitas (comfirmability) (Sukandarrumi, 2014).

\section{HASIL DAN PEMBAHASAN}

\section{Pembinaan Akhlak Melalui Pembelajaran PAI}

Pembinaan ialah suatu proses, kegiatan, dan metode pembinaan, pembaharuan, dan perbaikan yang dilakukan secara efisien dan efektif untuk mendapatkan hasil yang lebih optimal (Azmi, 2016).

Sementara dalam bahasa arab akhlak merupakan bentuk jamak dari istilah khuluq, yang berarti watak, perangai, tingkah laku, atau kepribadian, pada hakikatnya setiap jiwa sudah terdapat khuluq ( budi pekerti ) oleh sebab itu secara tidak sengaja ataupun sponta, tanpa perlu waktu lama untuk berfikir kita mampu melaksanakan berbagai macam perbuatan (Asmaran, 2012).

Dalam lingkungan sekolah guru dan kepala sekolah melaksanakan pembinaan akhlak siswa hal ini bisa berlangsung didalam ruang kelas ataupun saat ada jam pelajaran tambahan di luar sekolah. Berbagai macam cara diterapkan untuk membina akhlak siswa diantaranya bisa melalui materi khusus, nasehat, ceramah, dan melalui program-program lainnya. Pada kondisi ini, para guru ini dipercayakan untuk secara langsung menanamkan nilai-nilai akhlak pada siswanya. Selanjutnya, guru yang mengajarkan prinsip-prinsip akhlak yang sulit untuk dibahas mungkin secara khusus melalui mata pelajaran tertentu untuk memasukkannya dengan memperkenalkannya ke dalam mata pelajaran yang dipelajari.Dalam hal ini, guru-guru tersebut mendapat tugas agar dapat mengintegrasikan secara langsung nilai-nilai akhlak kepada siswa (Mahyudin, 2013). 
Dari hasil wawancara dengan kepala sekolah dan Guru PAI SMP Negeri 10 Lebong serta dari beberapa observasi yang telah dilaksanakan diketahui bahwa Pembinaan Akhlak siswa oleh Guru PAI melalui pembelajaran PAI di SMP Negeri 10 Lebong, antara lain dengan metode pembiasaan, metode teladan, metode bercerita dan metode sejarah. Sedangkan pembalajaran PAI di SMP Negeri 10 Lebong, dengan metode penugasan berupa tertulis atau portifolio dan praktik langsung.

\section{Pembinaan Akhlak Siswa Melalui Kegiatan Ekstrakurikuler Keagamaan}

Kegiatan ekstrakurikuler keagamaan adalah kegiatan yang dilakukan siswa di luar jam pelajaran/tatap muka dengan tujuan untuk meningkatkan kemampuan siswa dalam berbagai bidang seperti mengembangkan, mengintegrasikan, menghubungkan, menerapkan pengetahuan, sikap, dan keterampilan yang telah dimiliki. dipelajari ke dalam situasi nyata (dalam kehidupan nyata) (Departemen Agama, 2009).

Shalihin A Nasir mengemukakan bahwa kegiatan ekstrakurikuler ialah kegiatan yang dilaksanakan di sekolah atau di lingkungan masyarakat untuk menunjang program pengajaran. Khusus untuk mata pelajaran PAI, jenis kegiatan yang sering dilaksanakan di sekolah maupun di luar sekolah, seperti pesantren kilat, perkampungan muslim, santri ramadhan, peringatan hari-hari besar Islam, pengajian al-Qur'an dan sebagainya (Departemen Agama, 2013).

Dari hasil peneliti ini dapat diketahui bahwa pembinaan akhlak siswa oleh Guru PAI melalui kegiatan ekstrakurikuler keagamaan di SMP Negeri 10 Lebong dalam hal ini pelakdanaan sholat dan BTQ (Baca Tulis Qur'an) ialah dengan pembiasaan yakni Sholat tepat waktu, membaca al-Qur'an secara rutin dirumah, kemudian melalui ceramah, nasehat dan cerita kisah atau sejarah, serta monitoring dengan orangtua/wali siswa.

3. Kendala yang dihadapi dalam Pembinaan Akhlak di SMP Negeri 10 Lebong

Adapun yang menjadi kendala dalam pelaksanaan pembinaan akhlak siswa di SMP Negeri 10 Lebong ini antara lain terletak dalam ketiga faktor. Perama, Faktor kurangnya sarana komunikasi dalam hal ini Hand Phone (HP) yang dapat dipakai untuk mempermudah proses monitoring guru kepada siswa langsung atau guru melalui orang tua/ wali siswa. Sebab tidak semua orang secara tua/wali siswa memiliki HP, dan kalau pun memiliki HP, sebagian orangtua/wali siswa tidak mampu kalau harus terus-menerus membeli pulsa data.

Kedua, faktor transfortasi, dimana rumah tempat tinggal siswa yang sebagian sulit untuk dijangkau dengan kendaraan, sehingga harus ditempuh dengan berjalan kaki untuk sampai kerumah siswa tersebut, belum lagi kalau cuaca hujan jalan setapak yang masih tanah tentu menjadi sangat licin dan berlumpur.hal ini menyulitkan guru dalam mendatangi siswa kerumahnya untuk menyampaikan tugas pembelajaran PAI serta pembinaan akhlak siswa.

Ketiga, Faktor keadaan Pandemi Covid19 saat ini yang mengharuskan proses pembelajaran dan kegiatan ekstrakurikuler dalam pembinaan akhlak siswa dilaksanakan BDR (Belajar Dari Rumah). Dimana pembinaan akhlak siswa akan lebih mudah dan efektif kalau tatap muka dengan siswa secara langsung, rutin sehingga dapat memantau sikap, serta perkembangan perilaku siswa. Namun dengan adanya pandemic covid-19 ini untuk memantau atau memonitoring perkembangan sikap atau akhlak siswa kurang maksimal.

\section{KESIMPULAN}

Pembinaan Akhlak Siswa Oleh Guru PAI di SMP Negeri 10 Lebong, antara lain Pertama, melalui Pembelajaran PAI dengan metode pembiasaan, metode teladan, metode bercerita dan metode sejarah. Kemudian kedua, pembinaan akhlak Siswa melalui kegiatan ekstrakurikuler keagamaan dengan metode pembiasaan yakni sholat tepat waktu, membaca al-Qur'an secara rutin dirumah, kemudian ceramah, nasehat dan cerita kisah atau sejarah, serta monitoring dengan orangtua/wali siswa.

Kendala yang dihadapi Guru PAI dalam pembinaan akhlak siswa di SMP Negeri 10 Lebong ini antara lain ada tiga faktor. Pertama, Faktor kurangnya sarana komunikasi, Kedua faktor sarana transfortasi yang kurang baik, Ketiga Faktor keadaan Pandemi Covid-19 saat ini yang mengharuskan proses pembelajaran dan 
kegiatan ekstrakurikuler dalam pembinaan akhlak siswa dilaksanakan BDR (Belajar Dari Rumah).

\section{SARAN}

Bagi peneliti selanjutnya diharapkan dapat mengkaji lebih mendalam, membahas secara lebih detail dan mengembangkan metode agar ke depan penelitian mengenai tema ini lebih luas dan lengkap.

\section{UCAPAN TERIMA KASIH}

Ucapan terima kasih terutama ditujukan kepada IAIN Curup atas ilmunya, sehingga penulis dapat menyelesaikan artikel ini.

\section{DAFTAR PUSTAKA}

Arikunto, Suharsimi. 2002. Prosedur Penelitian; Suatu Pendekatan Praktek. Jakarta: Rineka Cipta.

Asmaran, As. 2012. Pengantar Studi Akhlak. Jakarta: PT Raja Grafindo Persada.

Azmi, Muhammad. 2016. Pembinaan Akhlak Anak Usia Pra Sekolah. Yogyakarta: Belukar.

Darajat, Zakiah.1993. Pendidikan Agama Islam, Solo: Ramadhani.

Daulay, Haidar Putra. 2014. Sejarah Pertumbuhan dan Perkembangan Pendidikan Islam di Indonesia, Jakarta: Kencana Prenada Media Group. .

Departemen Agama RI. 2009. Alquran dan Terjemahnya. Jakarta: Bumi Aksara.

Departemen Agama. 2013. Pedoman Peningkatan Keimanan Dan Ketakwaan Melalui Kegiatan Ekstrakurikuler. Jakarta: Ditjen Pembinaan Kelembagaan Agama Islam. Mahyudin. 2013. Kuliyah Akhlak Tasawuf. Jakarta: Kalam Mulia.

Moleong, J. Lexy. 2011. Metodologi Penelitian Kualitatif. Bandung: PT Remaja Rosdakarya.

Sukandarrumidi. 2014. Metodologi Penelitian Petunjuk Praktis untuk Penelitian Pemula. Yogyakarta: Gadjah Mada University Press.

Sulistyorini. 2009. Manajemen Pendidikan Islam: Konsep, Strategi, dan Aplikasi. Yogyakarta: Teras. 